\title{
TRADUCCÕES COMENTADAS DE POESIAS EM E TRADUZIDAS PARA LÍNGUAS DE SINAIS: UM MÉTODO DE PESQUISA EM CONSOLIDAÇÃO
}

\section{COMMENTED TRANSLATIONS OF POETRY IN AND TRANSLATED IN SIGN LANGUAGES: A CONSOLIDATION RESEARCH METHOD}

https://doi.org/10.46551/2179679320200005

\author{
Neiva de Aquino Albres \\ Universidade Federal de Santa Catarina - UFSC \\ neiva.albres@ufsc.br iD Ittps://orcid.org/0000-0003-1567-297X
}

RESUMO: $O$ presente artigo se propõe a contribuir com uma espécie de descrição e explicação da práxis de pesquisa em tradução, ou seja, dos modos de construir uma tradução comentada - método profícuo nos Estudos da Tradução. Pautados na análise dialógica do discurso de Bakhtin e do círculo (2010, 2016), utilizamos a pesquisa bibliográfica exploratória e análise qualitativa. Para tanto, selecionamos artigos científicos de traduções comentadas de poesias em e traduzidas para línguas de sinais no intuito de descrevê-los, analisá-los e compará-los. Elencamos as orientações metodológicas descritas pelos pesquisadores e propomos, ao final, um plano para a construção de traduções comentadas que envolvam obras em línguas de sinais, considerando a materialização do texto de partida ou de chegada em vídeo e as múltiplas semioses que permeiam a língua de sinais e a escrita acadêmica atualmente.

PALAVRAS-CHAVE: Tradução comentada; contexto acadêmico; Literatura em Sinais; tradução especializada; metodologia em tradução.

ABSTRACT: This paper proposes to contribute, in a kind of description and explanation of research praxis, that is, the ways of constructing of the genre commented translation, a useful research method in Translation Studies and its presentation of data. Based on one in the dialogical analysis of Bakhtin's discourse and the circle $(2010,2016)$, used was exploratory plus qualitative analysis. So we select commented translations from and to sign languages, more specifically gender poetic and scientific article format for comparison, description and analysis. We list the methodological guidelines described by the researchers and propose, at the end, a plan for the construction of commented translations involving works in sing language, considering the materialization of the source text or video arrival and the multiple semioses involving sing language and academic writing today.

KEYWORDS: commented translation; academic context; Signed Literature; specialized translation; translation methodology. 


\section{Introdução}

A produção de pesquisas afiliadas ao campo de Estudos da Tradução e Interpretação de Línguas de Sinais (Etils) está em expansão. Estes trabalhos se embasam em diferentes perspectivas teóricas, usam de distintas metodologias de pesquisas e constroem diversos objetos de estudos, contribuindo para a produção de conhecimento sobre processos, produtos de traduções e relações históricoculturais envolvendo as línguas de sinais ${ }^{1}$.

O interesse pela produção de tradução comentada por parte de alunos da graduação e pós-graduação é evidente, desde atividades acadêmicas pontuais até o desenvolvimento de pesquisas de mestrado e doutorado. Contudo, pouco se tem escrito sobre os modos de construir pesquisas nessa perspectiva, discutindo as metodologias empregadas e os instrumentos de construção dos dados.

Muitos estudos de traduções comentadas estão substanciados em estudos internacionais e nacionais, sem, no entanto, trazer de forma específica os aspectos teóricos ou chegar a uma concretização explícita das formas metodológicas e dispositivos de análise utilizados. Como pesquisadores, também construímos algumas experiências originais de tradução comentada de poesia em Língua Brasileira de Sinais (Libras), porém sem uma referência metodológica. Então, pretendemos apresentar ao leitor modos de fazer pesquisa em tradução comentada, reunindo experiências acumuladas de diferentes pesquisadores em torno de construções metodológicas e processos analíticos. Pela escassez de material que oriente como desenvolver esse tipo de pesquisa e tipo de arquitetônica discursiva (textual), justificamos a necessidade acadêmica e social desta pesquisa. A pergunta de pesquisa é: quais são os passos de uma metodologia de tradução comentada?

Relacionando ao tema de interesse desse trabalho, tratamos da tradução comentada como um gênero discursivo circunscrito ao domínio acadêmico e como uma metodologia de pesquisa em Estudos da Tradução em delineamento e consolidação. Dessa forma, nosso estudo se interessa pelo fenômeno da tradução como objeto de pesquisa e se volta para a construção e organização estrutural de artigos de "tradução comentada" enquanto prática acadêmica.

\footnotetext{
${ }^{1}$ VASCONCELOS, 2010; SANTOS, 2013.
} 
Tomamos como objeto de análise artigos publicados em periódicos no Brasil e que tenham feito uso de tradução comentada de poesias de ou para línguas de sinais.

Este texto tem por objetivos: 1) identificar e discutir os aspectos teóricos e práticos mobilizados na produção de tradução comentada de textos do gênero poético, com ênfase nas discussões das abordagens adotadas e nos aspectos epistemológicos envolvidos na tradução; 2) difundir, por meio de levantamento, obras acadêmicas (artigos científicos) de tradução comentada, acompanhada de discussão sobre a metodologia empregada, bem como de análise dos modos de construção do texto analítico que constitui "traduções comentadas".

\section{A tradução comentada como um gênero discursivo e um método de pesquisa}

A linguagem humana e dentro desse amplo espectro, a linguagem acadêmica, constrói historicamente uma arquitetônica de uso da linguagem para difundir a sistematização científica do conhecimento. Interessados em compreender a produção de uma tradução comentada, debruçamo-nos sobre o conceito de articulação arquitetônica, em que os elementos dessa escrita são constituintes de um todo e que o todo arquitetônico é composto de sentido, com suas partes unidas internamente e não desconexas umas das outras.

Ao delimitarmos nossa reflexão sobre o objeto "tradução comentada" como um acontecimento da linguagem, destacamos sua dupla atividade. Por um lado, o próprio trabalho de transladação de uma língua(gem) para outra, por outro lado, o uso da linguagem por uma metalinguagem para explicar esse acontecimento, uma forma de exteriorizar como a mente humana consegue resgatar de forma consciente o processo da tradução.

A escrita acadêmica como um objeto estético e ético assume um caráter particular que não pode ser dissociado do sujeito que a produz (autor-criador) e das condições materiais e históricas para sua execução. Assim, compreendemos que cada texto é singular e único. Entende-se, portanto, que

a forma de auto-suficiência, de auto-satisfação, inerente a tudo o que é esteticamente acabado, é uma forma puramente arquitetônica e impossível de ser transferida para a obra como 
material organizado, pois esta apresenta-se como uma entidade teleológica composicional onde cada momento e todo o conjunto estão voltados para um fim, realizam algo, servem para algo ${ }^{2}$.

Do modo como exemplifica Bakhtin ${ }^{3}$, ao tratar das formas arquitetônicas, os gêneros do discurso organizam-se em formas composicionais, relacionadas às escolhas verbais como um acontecimento histórico e social.

[...] deve-se ter em vista que cada forma arquitetônica é realizada por meio de métodos composicionais definidos; por outro lado, às formas composicionais mais importantes, às do gênero, por exemplo, correspondem, no objeto realizado, formas arquitetônicas essenciais ${ }^{4}$.

Para Bakhtin, a arquitetônica textual é a construção ou estruturação que une e integra o material, a forma e o conteúdo. Em sua visão, a forma arquitetônica nos permite sempre perguntar quem produziu, para quem e em que circunstâncias ${ }^{5}$.

Bakhtin ${ }^{6}$ compreende que o uso da linguagem está diretamente ligado aos diversos campos da atividade humana e que, portanto, tais usos são tão multiformes quanto esses campos de atividade. Cada campo de uso da língua elabora tipos relativamente estáveis de enunciados, os quais chamamos de gêneros do discurso. O campo científico tem consolidado, de forma mais abrangente, a escrita científica materializada em relatório de pesquisa (tese, dissertação, monografia), como também artigo científico, resumo expandido, resumo, ou com a produção de material para acompanhar uma exposição oral como o Poster/banner e slides para uma comunicação oral em evento científico. Dentre esses gêneros discursivos da esfera acadêmica, nos debruçaremos sobre o gênero artigo científico, especificamente, sobre aqueles que realizam tradução comentada de poesias.

\footnotetext{
2 BAKHTIN, 2010, p. 24.

${ }^{3}$ BAKHTIN, 2010.

${ }^{4}$ BAKHTIN, 2010, p. 24.

${ }^{5}$ SOBRAL, 2006.

${ }^{6}$ BAKHTIN, 2003.
} 
Sobre o artigo científico, Motta-Roth ${ }^{7}$ considera que tem uma composição relativamente estável de introdução, referencial teórico ou revisão de literatura, metodologia de pesquisa, análise e discussão dos dados, conclusão e referências. As revistas científicas consolidam formas de escritas ao estabelecer normas de publicação. Em artigos sobre o tema da tradução, quais são os funcionamentos de um estudo de tradução comentada? Qual é a estrutura arquitetônica dessa escrita? Qual é o lugar dado à metodologia de pesquisa na tradução comentada? Torres ${ }^{8}$ solidifica a concepção de tradução comentada como um gênero discursivo, sendo suas características:

- O caráter autoral: o autor da tradução é o mesmo do comentário; - O caráter metatextual: está na tradução comentada incluída a própria tradução por inteiro, objeto do comentário; a tradução está dentro do corpo textual (o texto dentro do texto);

- O caráter discursivo-crítico: o objetivo da tradução comentada é mostrar o processo de tradução para entender as escolhas e estratégias de tradução do tradutor e analisar os efeitos ideológicos, políticos, literários, etc. dessas decisões;

- O caráter descritivo: todo comentário de tradução parte de uma tradução existente e, portanto, reflete sobre tendências tradutórias e efeitos ideológico-políticos das decisões de tradução;

- O caráter histórico-crítico: todo comentário teoriza sobre uma prática de tradução, alimentando dessa forma a história da tradução e a história da crítica de tradução? .

A autora chama a atenção para aspectos arquitetônicos, dando destaque ao cunho descritivo desse tipo de texto. Williams e Chesterman ${ }^{10}$, quando abordaram as áreas de pesquisa em Estudos da Tradução, citam que a tradução comentada é um tipo de análise de texto e tradução (Texts Analysis and Translation). Nesse sentido, os autores trataram a tradução comentada ao mesmo tempo como um campo de estudo e como um método de pesquisa.

"Uma tradução comentada (ou tradução anotada) é uma forma de pesquisa introspectiva e retrospectiva em que o tradutor traduz um texto e, ao mesmo tempo, escreve um comentário a respeito de seu processo de tradução" ${ }^{11}$. Explicando melhor, esses comentários escritos pelo tradutor-pesquisador podem

\footnotetext{
${ }^{7}$ MOTTA-ROTH, 2003.

8 TORRES, 2017.

${ }^{9}$ TORRES, 2017, p. 18.

${ }^{10}$ WILLIAMS; CHESTERMAN, 2002.

${ }^{11}$ WILLIAMS, CHESTERMAN; 2002, p. 07. No original: "The type of research work proposed can be ascribed to the subarea of Text Analysis and Translation Studies called 'Annotated Translation' or 'Translation with Commentary'. Tradução nossa.
} 
se organizar de diferentes formas, podendo abordar "a tarefa de traduzir, análise do texto-fonte e do contexto em que ele foi escrito ou ainda justificativas sobre os problemas enfrentados e as soluções propostas no decorrer do processo tradutório"12, como uma análise crítica envolvendo os textos trabalhados na tradução. Nesses dois focos, deve-se fazer uma análise. Evidencia-se que uma tradução comentada incorpora decisivamente a análise de fontes, uma vez que se inicia pelo estudo do texto tanto de aspectos linguísticos como extralinguístico, caracterização do gênero discursivos do material da tradução, e, em igual valor, o processo, ou seja, vários estágios que passou durante a tradução, descrevendo o processo interno de tomada de decisão do tradutor ${ }^{13}$.

Nesta perspectiva, o trabalho de tradução comentada envolve atividades antes da tradução, durante a tradução e após a tradução. Precede a tradução o estudo das fontes consultadas, das pesquisas desenvolvidas para conhecimento da obra e seu período histórico, como o estudo da vida e estilo de produção do autor. O Estudo durante a tradução submerge a resolução dos problemas de tradução. Assim, o comentário "incluirá [...] uma análise de aspectos do texto fonte e uma justificativa fundamentada dos tipos de solução que se chegou para tipos específicos de problemas de tradução" ${ }^{14}$. As escolhas tradutórias vão incidir inevitavelmente a questões subjetivas e pessoais, desde a escolha lexical até estrutura sintático-expressiva, "dentro de paradigmas de palavras, parcialmente objetivas (baseadas na disponibilidade literária) e parcialmente subjetivas na memória e habilidades pessoais do tradutor)"15. Igualmente, a estética da tradução é marcada pelo tradutor. Nesse sentido, Álvarez ${ }^{16}$ classifica a tradução comentada como um tipo de "estudo de caso".

O estudo do tipo "tradução comentada" pode ser feito pelo próprio tradutor como também pode ser executado por uma equipe de pesquisadores que farão uso de instrumentos metodológicos para apreender o processo de tradução, seja

\footnotetext{
12 ZAVAGLIA, RENARD, JANCZUR, 2015, p. 333.

${ }^{13}$ WILLIAM, CHESTERMAN, 2002.

14 Ibid, p. 07. No original: [...] "will include [...] an analysis of aspects of the source text, and a reasoned justification of the kinds of solution you arrived at for particular kinds of translation problems". Tradução nossa.

${ }^{15}$ LEVÝ, 1967/2012, p. 76. No original: "inside word paradigms, partly objective (based on literary availability) and partly subjective (based on the memory and personal skills of the translator)". Tradução nossa.

${ }^{16}$ ÁLVAREZ, 2007.
} 
ele retrospectivo ou no momento da tradução. Uma tendência é denominar de "tradução comentada" o estudo que incorpore o autor da tradução à pesquisa e escrita científica, tendo como princípio "dar visibilidade e voz ao tradutor".

Nesse processo, os tradutores-pesquisadores desenvolvem a análise de aspectos da "macro e da microestrutura da obra, a fim de observar se houve perdas, compensações ou ganhos na tradução, entendendo que essa é a função da crítica tradutória", como salienta Paes ${ }^{17}$. A tradução comentada se dedica a analisar tanto aspectos extra-textuais como intra-textuais. A seguir, apresentamos alguns aspectos do processo de execução da tradução comentada e do registro desse processo, como: descrição pré-tradução ou paralelo à tradução:

Entre os procedimentos favoritos está um estudo prévio aprofundado não só do texto a ser traduzido, mas de uma extensa lista de fontes de documentação, incluindo desde obras de referência a estudos específicos sobre os textos e seus autores. Essas fontes, tanto enciclopédicas como especializadas, são indispensáveis para a construção do processo tradutório em si e para a construção dos de comentários sobre o processo que sejam pertinentes ${ }^{18}$.

Outra possibilidade é "antes da discussão das escolhas tradutórias, [se fazer] uma introdução sobre o tipo de texto a ser traduzido". Assim, o autor faz "uma exposição sintética dos principais traços desse tipo textual, a que se segue uma discussão minuciosa da tradução do texto-fonte, repartido em pequenas

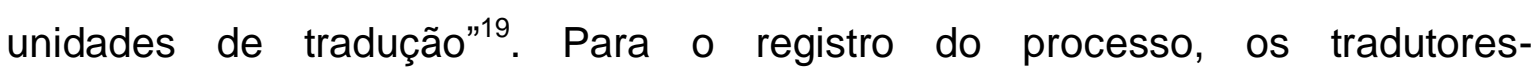
pesquisadores devem anotar os pensamentos, reflexões, tendências interpretativas e escolhas tradutórias como suas movimentações em um "diário de tradução", assim como se faz diário de campo em estudos de caso ${ }^{20}$.

\section{Metodologia de pesquisa}

Esta pesquisa inscreve-se em uma abordagem qualitativa, constituindo-se

\footnotetext{
${ }^{17}$ PAES, 1990.

${ }^{18}$ COSTA, 2017, p. 12.

${ }^{19}$ COSTA, 2017, p. 14.

${ }^{20}$ ROSSI, 2014.
} 
como pesquisa bibliográfica exploratória. Traçamos como objetivo analisar formas metodológicas e dispositivos de análise utilizados em traduções comentadas de poesias em e traduzidas para línguas de sinais publicadas no Brasil.

Para tanto, levantamos um corpus de traduções comentadas definindo como critério a seleção de artigo publicado em revista científica e resumo expandido publicado no Congresso Nacional de Pesquisas em Tradução e Interpretação de Libras e Língua Portuguesa da UFSC, por serem trabalhos de extensão similar e por terem passado por avaliação de comissão científica ou parecerista. O referido congresso é desenvolvido desde 2008 (bianual) e tem se consolidado como um evento importante da área de Etils, congregando pesquisadores de todo o país.

Selecionamos a tradução comentada do gênero poesia, pois a planificação em um mesmo gênero discursivo pode ser item importante para a comparação dos trabalhos e por pensarmos ter um número substancial para análise de trabalhos desse gênero.

A primeira etapa consistiu no levantamento das traduções comentadas de poesias em e traduzidas para língua de sinais no Brasil. Os trabalhos foram extraídos do mapeamento de artigos científicos publicados em revistas brasileiras, realizado recentemente por Mendonça (2019), e dos Anais do referido Congresso. Assim, chegou-se ao corpus de seis artigos, cinco envolvendo Língua Brasileira de Sinais - Libras e um envolvendo Língua de Sinais Britânica (LSB = British Sign Language-BSL).

Quadro 1 - Trabalhos levantados a partir dos mapeamentos (2010-2019)

\begin{tabular}{|l|l|l|l|}
\hline Ano & \multicolumn{1}{|c}{ Autores } & \multicolumn{1}{|c}{ Direção } & \multicolumn{1}{|c|}{ Qualis $^{\mathbf{2 1}}$} \\
\hline $\mathbf{2 0 1 0}$ & NICOLOSO, Silvana & Libras para português escrito & Revista A1 \\
\hline $\mathbf{2 0 1 3}$ & $\begin{array}{l}\text { WEININGER, Markus J.; et } \\
\text { al. }\end{array}$ & Libras para português escrito & Congresso \\
\hline $\mathbf{2 0 1 4}$ & KLAMT, Marilyn Mafra & Libras para português escrito & Revista B2 \\
\hline
\end{tabular}

${ }^{21}$ Classificação de periódicos quadriênio 2013-2016. 
\begin{tabular}{|l|l|l|l|}
\hline 2016 & SANTOS, Saionara & Português escrito para Libras & Revista B2
\end{tabular} Figueiredo.

2017 NASCIMENTO, Vinícius; Português escrito para Libras Revista B1 MARTINS, Vanessa R. de O., SEGALA, Rimar R.

2019 SILVA, Marília Duarte da; Libras para português escrito Revista B2 ALBRES, Neiva de Aquino

Fonte: Produzido pela autora

Após a seleção do corpus da pesquisa, desenvolvemos a leitura completa dos trabalhos e a seleção das informações sobre a metodologia empregada e dos aspectos analisados em traduções comentadas de poesias.

\section{Análise de Traduções comentadas de poesias em línguas de sinais publicadas no Brasil}

Para a nossa discussão, analisaremos as traduções de poesia disponíveis em revista científicas on-line (quadro 1), e assim, apreendemos sua forma arquitetônica de produção. Entendemos que, devido ao escopo deste artigo, não observaremos todas as especificidades possíveis, mas escolhemos dois pontos, são eles: 1)Aspectos analisados nos artigos de traduções comentadas; 2) Modos de fazer a pesquisa (etapas da metodologia).

\subsection{Aspectos analisados nos artigos de traduções comentadas}

Quadro 2 - Síntese dos trabalhos levantados

POESIA 1: Nicoloso $^{22}$ discutiu os desafios desse tipo de tradução apresentando sua própria experiência na realização de uma tradução comentada de um poema em Língua de Sinais Britânica (British Sign Language - BSL), intitulado "Os Cinco Sentidos", de Paul Scott, e a sua tradução para a Língua Portuguesa escrita. O aspecto central da discussão é a intraduzibilidade da poesia.

${ }^{22}$ NICOLOSO, 2010. 
POESIA 2: Weininger, et al. $^{23}$ analisaram três traduções do poema "Homenagem Santa Maria" de Godinho ${ }^{24}$ em Libras para um poema escrito em português, discutindo os aspectos formais da poesia em língua de sinais e problematizando a retextualização de ritmo, rima, divisão em versos e estrofes.

POESIA 3: Klamt ${ }^{25}$ tratou de estratégias de tradução do poema em Libras "Voo sobre Rio", da poetisa Fernanda Machado para a Língua Portuguesa. Os conceitos discutidos são de traduzibilidade de poesia, os mitos da tradução, domesticação x estrangeirização.

POESIA 4: Santos $^{26}$ expôs uma experiência tradutória do poema na língua portuguesa "Debussy", de Manuel Bandeira, para a Libras, enfatizando o posicionamento e as dificuldades do tradutor no processo de tradução. Os conceitos trabalhados são a domesticação e a estrangeirização.

POESIA 5: Nascimento, Martins e Segala ${ }^{27}$ analisaram o processo tradutório do português para a Libras da poesia "Deficiência", de Alexandre Filordi de Carvalho (ouvinte), com base na teoria da transcriação, construída por Haroldo de Campos.

POESIA 6: Silva e Albres ${ }^{28}$ apresentaram as estratégias adotadas na tradução da poesia em Libras "Amor à primeira vista..." da poetisa surda Ananda Elias, para o português escrito. Trabalharam com os efeitos estéticos e as escolhas de tradução realizadas.

Fonte: Produzido pela autora

Todos os trabalhos apontam para as marcas das escolhas subjetivas dos tradutores, da viabilidade de tradução de poesia e de sua traduzibilidade. Para Campos $^{29}$, entre os textos artísticos mais difíceis de se traduzir, costuma se apontar os poéticos. "Há quem diga que poemas só devem, ou só podem, ser traduzidos por poetas", pois o tradutor precisa também saber a técnica de versejar (fazer versos) para dar o tom à poesia. Acrescentamos que traduzir a poesia e ao mesmo tempo refletir sobre o processo, estudar a atividade e produzir

\footnotetext{
${ }^{23}$ WEININGER et al., 2014.

${ }^{24}$ GODINHO, 2013.

${ }^{25}$ KLAMT, 2014.

${ }^{26}$ SANTOS, 2016.

${ }^{27}$ NASCIMENTO, MARTINS; SEGALA, 2017.

${ }^{28}$ SILVA; ALBRES, 2019.

${ }^{29}$ CAMPOS, 1986, p. 60.
} 
conhecimento requer a díade poeta-pesquisador. Além de viver o poema, sentir e criar, é preciso refletir.

Assim sendo, observa-se, na verdade, dois produtos: um consiste na própria poesia traduzida, outro, em um artigo, isto é, no texto acadêmico científico que versa sobre os versos construídos, sobre as letras e movimentos dos signos, sobre os efeitos de sentido mobilizados no processo da tradução.

Os artigos analisaram a fidelidade, equivalência, classificadores, rima entre outros aspectos. A tradição tradutória de poesias ${ }^{30}$ privilegiaria fundamentalmente a recriação, em outra língua, da dimensão formal dos poemas (seus aspectos fonológicos e sua métrica), em detrimento, até certo ponto, de seus aspectos semânticos. Por sua vez, Laranjeira ${ }^{31}$ considera ser necessário uma "totalização essencial" que essencialmente envolve equilíbrio entre as equações fonológicas e semânticas.

\subsection{Modos de fazer a pesquisa (etapas da metodologia)}

Estudos metodológicos de tradução são um grande desafio. Ao se propor a utilização de um procedimento de pesquisa, tipos de análise e formas de apresentar isso em um texto do gênero artigo científico como um gênero já consolidado, é preciso atender a essas formas estáveis e recorrentes de explicitação da metodologia da pesquisa. Na primeira coluna do quadro 2 indicamos o autor e ano como também a direção da tradução, de língua se sinais para língua vocal ${ }^{32}$ (LS para LV) ou da língua oral para a língua de sinais (LV para a LS), e na segunda coluna compilamos as informações fornecidas pelos autores sobre a metodologia emprega na tradução comentada.

Quadro 3 - Indicação das etapas da metodologia de tradução comentada de poesias em e para línguas de sinais proposta pelos autores.

\section{Autor-ano e}

Descrição

\footnotetext{
${ }^{30}$ CAMPOS, 2010, 2013.

${ }^{31}$ LARANJEIRA, 2012.

${ }^{32}$ Há diferentes formas de denominar as línguas a partir da distinção de modalidades. Para uma discussão sobre distinção entre línguas de sinais e línguas vocais ver Rodrigues (2018) que tecnicamente as denomina de línguas gestuais-visuais e línguas vocais-auditivas.
} 


\begin{tabular}{|c|c|}
\hline direção & \\
\hline $\begin{array}{l}\text { NICOLOSO } \\
(2010)\end{array}$ & $\begin{array}{l}\text { "Como aspecto metodológico utilizou-se a abordagem } \\
\text { qualitativa"33. Para a realização da pesquisa da tradução } \\
\text { comentada focou em estudar o texto de partida, analisar a } \\
\text { linguagem, perceber a intenção do texto e conhecer o público } \\
\text { alvo. Com isto, optou-se por manter a coesão textual e a } \\
\text { forma de registro para adequar ao estilo, analisar o propósito } \\
\text { comunicativo da tradução, perceber a informação do texto de } \\
\text { partida considerando o âmbito da situação cultural que o } \\
\text { condicionou. E por fim, no texto de chegada, houve a tentativa } \\
\text { de privilegiar o contexto cultural e situacional com o propósito } \\
\text { de alcançar o objetivo de uma tradução, ou seja, passar a } \\
\text { mensagem e comunicar, para isto analisou-se a forma como a } \\
\text { linguagem é usada para produzir efeitos poéticos no poema } \\
\text { em língua de sinais }{ }^{34} \text {. }\end{array}$ \\
\hline $\begin{array}{l}\text { POESIA } 2 \\
\text { WEININGER, } \\
\text { et al. } \\
\text { (2013) } \\
\text { LS para LV }\end{array}$ & $\begin{array}{l}\text { O grupo de pesquisa propôs que diferentes tradutores } \\
\text { trabalhassem no texto, desenvolvendo, então, três traduções } \\
\text { distintas. A primeira pode ser considerada de natureza mais } \\
\text { interdiscursiva, comunicacional e performática. A segunda é } \\
\text { mais formalmente direcionada à estrutura linguística, poética, } \\
\text { literária e ainda à disposição gráfica geral do texto traduzido } \\
\text { em português, mas sem se esquecer da referência à } \\
\text { performance do poema-fonte em Libras. Por sua vez, a } \\
\text { terceira dispõe de uma orientação interlinguística, intermodal, } \\
\text { intercultural e experimental, estabelecendo mais relações } \\
\text { entre as culturas textuais fonte e alvo, isto é, entre as } \\
\text { realidades contextuais do texto em Libras e as realidades } \\
\text { contextuais do texto traduzido em português. }\end{array}$ \\
\hline $\begin{array}{l}\text { KLAMT } \\
\text { (2014) } \\
\text { LS para LV }\end{array}$ & 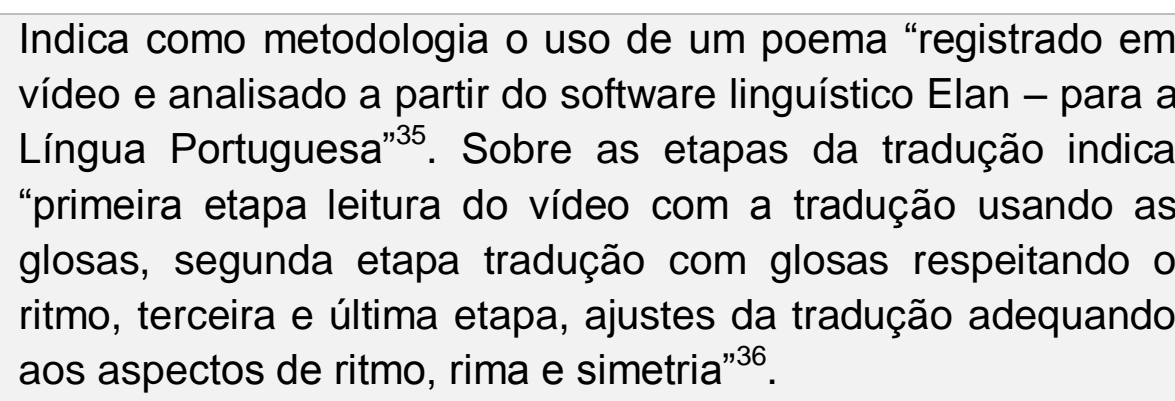 \\
\hline
\end{tabular}

\footnotetext{
${ }^{33}$ NICOLOSO, 2010, p. 312.

${ }^{34}$ NICOLOSO, 2010, p. 313.

${ }^{35}$ KLAMT, 2014, p. 107.

${ }^{36}$ KLAMT, 2014, p. 113.
} 

POESIA 4 Utiliza-se da metodologia que Nicoloso ${ }^{37}$ utilizou em sua tradução, utilizando a abordagem qualitativa de Triviños $^{38}$.
SANTOS Para a realização desta pesquisa, estudou-se 0 texto de (2016) LV para LS partida, analisando a intenção do texto, a linguagem, com o intuito de se manter a coesão textual. A forma de registro escolhida foi a filmagem, em virtude da língua alvo ser viso- espacial (Libras). No texto de chegada, privilegiou-se o contexto cultural, analisando as tentativas de produzir efeitos poéticos na tradução do poema ${ }^{39}$.

POESIA 5
NASCIMENTO,
MARTINS e
SEGALA
(2017)
LV para LS

POESIA 6

SILVA e ALBRES (2019)

LS para LV
O processo de transcriação foi realizada por três tradutores. Descrevem quatro etapas: (i) Preparação, (ii) Produção, (iii) Edição e (iv) Revisão. Seguida dos comentários com as Estratégias transcriativas ${ }^{40} \mathrm{Na}$ preparação os dois tradutores ouvintes fizeram uma primeira "tradução explicativa" para o tradutor surdo. Na produção, dividiram em estrofes e criaram as expressões de destaque. Para edição decidiram as legendas e imagens e na revisão o vídeo foi revisto.

Pautados em uma abordagem qualitativa de pesquisa, afirmam utilizar a metodologia de "estudo de caso" ${ }^{41}$. Nesse sentido, "conduzidas pelos princípios das características da tradução comentada apreendida como um gênero acadêmicoliterário, conduzimos nossa análise da poesia traduzida" ${ }^{42}$.

Descrevem em três etapas: observações detalhadas do vídeo da poesia análise da expressão corporal, "mergulhar na visualidade da expressão corpórea". Segundo: produziram a uma primeira versão da tradução "tomando nota das motivações para as escolhas tradutórias". Em uma terceira etapa foram analisadas atentamente as repetições, rimas, ritmos e outras funções estéticas do texto de partida para guiarem nossas escolhas tradutórias para a versão final (SILVA; ALBRES, 2019, p. 07).

Fonte: Produzido pela autora

\footnotetext{
${ }^{37}$ NICOLOSO, 2010.

${ }^{38}$ TRIVIÑNOS, 1987; SANTOS, 2016, p. 99.

${ }^{39}$ SANTOS, 2016, p. 100.

${ }^{40}$ NASCIMENTO, MARTINS, SEGALA, 2017, pp. 1865 - 1866.

${ }^{41}$ SILVA; ALBRES, 2019, p. 06.

${ }^{42}$ SILVA, ALBRES, 2019, p. 7.
} 
Nicoloso e Santos ${ }^{43}$, alunas do Programa de Pós-graduação em Estudos da Tradução (PGET) indicam que a tradução comentada publicada foi desenvolvida em uma disciplina do curso da UFSC. Weininger et al. ${ }^{44}$ mencionam ser uma pesquisa do Grupo de Pesquisa em Tradução de Poesia da Universidade Federal de Santa Catarina (UFSC). Nascimento, Martins e Segala (2017) afirmam ser uma pesquisa do Grupo de Estudos Discursivos da Língua de Sinais (GEDiLS) da Universidade Federal de São Carlos (UFSCar). A tradução comentada de Silva e Albres ${ }^{45}$ foi fruto de um trabalho no curso de graduação em Letras-Libras da UFSC. A partir desses dados, podemos registrar que a tradução comentada está ligada ao ensino e a formação de tradutores e pesquisadores no campo dos Estudos da Tradução.

Constatamos que os autores detalham o processo da tradução, apresentando as etapas. Contudo, não se atém à descrição do processo de pesquisa. Apenas Nicoloso, Santos, Silva e Albres ${ }^{46}$ apresentaram explicitamente usar abordagem qualitativa e usar a metodologia de tradução comentada, mas nem todos apresentam uma seção de metodologia de pesquisa no artigo bem delimitada.

Weininger, et al. ${ }^{47}$ apresentaram uma seção "Resumo da metodologia utilizada", Nicoloso ${ }^{48}$ organiza o artigo com uma seção "Tradução de poesias em língua de sinais: um desafio fascinante", $\operatorname{Santos}^{49}$ tem uma seção de "Comentários sobre o processo de tradução do poema 'Debussy", Klant ${ }^{50}$ apresenta uma seção de "Comentários sobre o processo", por sua vez, Silva e Albres $^{51}$ apresentam uma seção denominada "Metodologia", em que explicitam a metodologia da pesquisa e logo em seguida a metodologia da tradução, na mesma seção. As autoras indicam que no processo da tradução foram "tomando nota das motivações para as escolhas tradutórias", mas não explicitam qual instrumento foi usado, se um diário ou fichas de registro.

\footnotetext{
${ }^{43}$ NICOLOSO, 2010; SANTOS, 2016.

${ }^{44}$ WEININGER, et al., 2014.

${ }^{45}$ SILVA E ALBRES. 2019.

${ }^{46}$ NICOLOSO. 2010; SANTOS, 2016; SILVA; ALBRES, 2019.

${ }^{47}$ WEININGER, et al., 2014.

${ }^{48}$ NICOLOSO, 2010.

${ }^{49}$ SANTOS, 2016.

50 KLANT, 2014.

${ }^{51}$ SILVA; ALBRES, 2019, p. 07.
} 
Ponderando sobre as reflexões e os levantamentos discutidos sobre a importância da escolha de um procedimento metodológico modelo que garanta a cientificidade da tradução comentada durante o desenvolvimento deste tipo de estudo, apesar de alguns artigos apresentarem as etapas da tradução não apresentam explicitamente a abordagem de pesquisa (qualitativa ou quantitativa), o tipo de pesquisa (exploratória, descritiva, explicativa), metodologia empregada (estudo de caso, entre outros), os procedimentos da pesquisa e os modos de registro dos comentários produzidos pelos tradutores (diário, fichas, caderno de anotações), não mencionam também a natureza da pesquisa (pura ou aplicada).

Verificamos, então, após os artigos levantados e discutidos neste estudo e conforme a literatura dos estudos da tradução, que não há uma uniformidade para os instrumentos, técnicas e modos de registro dos comentários. Mas esse fato não exime os pesquisadores de apresentar explicitamente o seu desenho metodológico. Esse conjunto de pesquisas não seguiu algum protocolo ou instrumento de pesquisa como indicado na literatura (diário de tradução, divisão em unidades de tradução, construção de tabelas com as diversas fases da tradução, entre outras), pelo menos não foi especificado no artigo.

Em uma perspectiva dialógica da linguagem ${ }^{52}$, o uso da linguagem em seus diversos campos é multiforme, mas no gênero artigo científico há elementos essenciais e estáveis que precisam ser registrados e a metodologia é um item essencial. Nesse sentido, propomos algumas recomendações para a metodologia, com etapas da pesquisa do tipo de tradução comentada, que poderiam ser apresentadas em artigo científico, como pode ser visto no quadro 3.

Apresentamos um contraste entre dois pontos da pesquisa em tradução comentada no Brasil. Os dados de traduções comentadas de poesias em línguas de sinais privilegiaram fundamentalmente o fazer tradutório, a dimensão do tradutor (seus aspectos do procedimento da tradução), em detrimento, até certo ponto, de seus aspectos metodológicos e científicos da tradução comentada realizada pelo pesquisador. São dois pontos que deveriam ser contemplados na tradução comentada em uma seção sobre a metodologia da pesquisa. Nessa perspectiva, Bassnett ${ }^{53}$, assim como Saldanha e O'Brien ${ }^{54}$, contrapõem a prática

\footnotetext{
${ }^{52}$ BAKHTIN, 2003.

${ }^{53}$ BASSNETT, 2003.
} 
de pesquisa em tradução e uso de estudo de caso, a qual seria norteada por uma falta de explicitação das técnicas e procedimentos sistematizados para a produção da pesquisa em tradução, indicando a necessidade do equilíbrio entre as equações do fazer procedimental da tradução e do fazer científico. Consideramos que essa perspectiva prática de tradução tende a simplificar e a enfraquecer os estudos da tradução como um campo científico, já que sua estrutura formal afastaria o leitor do complexo processo da pesquisa, porventura, podendo apresentar os instrumentos para serem replicados por outros pesquisadores.

A rigor, traduções comentadas em línguas vocais indicam explicitamente alguns desses pontos, como o uso de Diário de tradução ${ }^{55}$, documentação ${ }^{56}$, apresentação dos modos de análise dos dados ${ }^{57}$, apresentação bilíngue com 0 texto de partida e o texto de chegada $^{58}$, como também os comentários do tradutor $^{59}$ como elementos essenciais.

No intuito de responder às questões levantadas na introdução desse artigo sobre a estrutura de um estudo de tradução comentada, sobre a composição do gênero e a arquitetônica dessa escrita, como também sobre elementos essências da metodologia de pesquisa na tradução comentada, construímos o quadro 3 indicando recomendações para a escrita do título do artigo, do resumo, da metodologia e para a análise da tradução.

Quadro 4 - Recomendações para uso de metodologia de tradução comentada

Recomendações:

1.Título do artigo: a indicação da tradução comentada no título é opcional;

2. Resumo: deve apresentar no resumo a tradução comentada como a metodologia, o uso do estudo de caso e pesquisa qualitativa, como os outros elementos essenciais ao resumo;

3. Metodologia: é salutar apresentar uma seção de metodologia no artigo em que se apresente de forma detalhada a pesquisa de tradução comentada,

\footnotetext{
${ }^{54}$ SALDANHA, O'BRIEN, 2013.

${ }^{55}$ ROSSI, 2014.

${ }^{56}$ DURÃO; DURÃO, 2017.

${ }^{57}$ SALDANHA; O'BRIEN, 2013.

${ }^{58}$ FREITAS; TORRES; COSTA, 2017.

59 TORRES, 2017.
} 
incluindo seus instrumentos e procedimentos:

- Apresentar a tradução comentada como de abordagem qualitativa, tipo de pesquisa descritiva e como um "estudo de caso";

- Apresentar a pesquisa feita paralela à tradução (documentação, dicionários, sites, etc.);

- Registrar o processo em um "diário de tradução" que servirá como material para os comentários da tradução;

- A tradução deve ser realizada por etapas, envolvendo revisões, alterações, ponderações iniciais. Registrar todas as impressões, excitações, sentidos construídos no processo em diário de tradução;

- Pode-se organizar um diário em que cada trecho original é disposto em tabelas, de forma numerada, na ordem em que aparece no texto, e nas colunas apresentar as versões e os comentários do tradutor por dia de trabalho;

- Explicitar se houve grandes intervalos entre a tradução e as releituras e alterações;

\section{Análise da tradução:}

- Apresentar a obra, o autor e o contexto histórico da obra traduzida;

- Fazer uma descrição pré-tradução;

- Fazer uma descrição da tradução, quantas versões da tradução foram desenvolvidas, a depender do espaço do artigo e do tamanho do texto apresentá-las na íntegra;

- Apresentar pelo menos o texto de partida e a versão final da tradução. Sugerimos a apresentação do texto de partida antes do texto traduzido, podendo usar a forma canônica de duas colunas com os textos paralelos, ou mesmo de três colunas com os textos de partida e chegada paralelos, assim como os comentários relacionados a cada trecho;

- Convém dividir o poema em estrofes (unidades de tradução) numeradas para poderem ser recuperadas no decorrer do texto analítico. Para cada estrofe indique o tempo de início e término no vídeo ou subdivida o vídeo para acesso direto ao excerto.

- Disponibilize o link do vídeo em uma plataforma de sua autoria para não correr o risco de ser apagada futuramente;

- Após a apresentação global da sua tradução, passar a problematizar o processo e a discutir sobre as escolhas tradutórias;

- Os comentários "brutos" do diário de tradução são selecionados em excertos para compor o artigo, como uma memória do vivido no processo de tradução e em outro momento, da escrita do artigo, o autor-tradutor reelabora e aprofunda a análise;

- Na análise, o uso da glosa deve ser associado à ilustração do vídeo com prints da sinalização. Procure trabalhar com uma sequência de sinais em detrimento de sinais isolados, assim o ponto de análise fica mais bem contextualizado para o leitor; 
- Os comentários, propostos ao longo da tradução, podem ser numerados em sequência ou agrupados por categorias analíticas. Nessa parte do artigo, recomenda-se dividir em trechos menores o texto da tradução para detalhar a discussão.

Fonte: Produzido pela autora

Apontamos no quadro 4 algumas possibilidades de registro das etapas da tradução comentada e a importância de sua descrição. A proposta de metodologia de tradução comentada foi baseada em evidências tanto de pesquisadores de línguas de sinais quanto de línguas vocais-auditivas.

\section{Considerações finais}

O presente estudo evidenciou a não padronização de metodologias de tradução comentada para língua de sinais em traduções de poesias. Nos estudos analisados prevaleceu a metodologia da tradução em detrimento da metodologia de pesquisa. Os autores são tradutores e também pesquisadores vinculados a programas de pós-graduação.

A partir dos artigos analisados e da revisão de literatura, podemos afirmar que a "tradução comentada" pode se configurar de diferentes formas, como: 1) um método de pesquisa, 2) como um gênero discursivo do tipo artigo científico, ou 3) uma atividade didática a fim de se ensinar tradução.

Algumas etapas mostraram-se fundamentais para manter a credibilidade dos estudos de tradução no campo científico. Diante das evidências, desenvolvemos recomendações para o emprego de metodologia de tradução comentada sobre a língua de sinais a partir de cinco etapas: 1) estudo prétradução; 2) no processo de tradução o registro dos comentários em diário de tradução; 3) o registro da documentação e pesquisa desenvolvida; 4) apresentar a obra, o autor, o contexto, o texto de partida e a tradução em suas versões no artigo; 5) análise e ajustes desenvolvidos pelo tradutor.

Dessa forma o autor do artigo de tradução comentada precisa explicitar o método de pesquisa como um estudo de caso, como uma tradução comentada e análise qualitativa. Deve explicitar os procedimentos de construção dos dados 
como os de análise dos dados.

Acredita-se que estes passos possam auxiliar para que os resultados das traduções comentadas de poesias em e para a Libras apresentem maior confiabilidade científica e maior aplicabilidade, ou seja, possam ser replicados por outros pesquisadores.

\section{Referências}

ÁLVAREZ, Ana María García. Evaluating Students' Translation Process in Specialised Translation: Translation Commentary. The Journal of Specialised Translation - JoSTrans's. Table of Contents: Issue 07 - January 2007. Disponível em: <https://www.jostrans.org/issue07/art_alvarez.pdf>. Acesso em: 21 jul 2019.

BAKHTIN, M. O problema do conteúdo, do material e da forma na criação literária. In: BAKHTIN, M. Questões de literatura e de estética: A teoria do romance. Trad. Aurora Fornoni Bernardini et al. 6. ed. São Paulo: HUCITEC, 2010, p.13-57.

BAKHTIN, M. M. Para uma filosofia do ato responsável. Tradução de Valdemir Miotello e Carlos Faraco. São Carlos: Pedro \& João Editores, 2010b [1920-24].

Os gêneros do discurso. In: BAKHTIN, M. Estética da criação verbal. Trad. Paulo Bezerra. 4. ed. São Paulo: Martins Fontes, 2003, p.261-306.

BASSNETT, S. Estudos de Tradução. Fundamentos de uma disciplina. Tradução de Viviana de Pádua Figueiredo. Lisboa: Fundação Calouste Gulbenkian, 2003, p. 64-71.

CAMPOS, Haroldo. Da tradução como criação e como crítica. In: CAMPOS, Haroldo. Metalinguagem e outras metas. 4.ed. São Paulo: Perspectiva, 2010. p.31-48.

COSTA, Walter Carlos. Novos experimentos em tradução comentada - Prólogo. In: DURÃO, Adja Balbino de Amorim Barbieri; DURÃO, Aylton Barbieri (orgs). De Horizonte a Horizonte: traduções comentadas. Florianópolis: Insular, 2017. pp 1115.

DURÃO, Adja Balbino de Amorim Barbieri; DURÃO, Aylton Barbieri (orgs). De Horizonte a Horizonte: traduções comentadas. Florianópolis: Insular, 2017.

FREITAS, Luana Ferreira de; TORRES, Marie Hélène Catherine; COSTA, Walter Carlos (orgs). Literatura traduzida: tradução comentada e comentários da tradução. Fortaleza: Substânsia, 2017. pp15-35.

HURTADO ALBIR, Amparo. Traducción y traductología. Madrid: Cátedra, 2001.

KLAMT, Marilyn Mafra. Tradução comentada do poema em língua brasileira de sinais "Voo sobre rio". Belas Infiéis, v. 3, n. 2, p. 107-123, 2014b. Disponível em: $<$ http://periodicos.unb.br/index.php/belasinfieis/article/view/11285>. Acesso em: 21 jul 2019.

LARANJEIRA, Mário. Sentido e significância na tradução poética. Estudos Avançados, V. 26 N. 76, p.29-37. 2012. Disponível em: 
<http://www.revistas.usp.br/eav/article/view/47536>. Acesso em: 24 abr. 2019.

LEVÝ, Jiří. Translation as a Decision Process, in: To Honor Roman Jakobson, 3 vols, The Hague: Mouton, 2, 1967. 1171-1182. Traduçao in cadernos de tradução. https://periodicos.ufsc.br/index.php/scientia/article/download/19804237.2012n11p72/22525

MENDONÇA, Victor.Mapeamento dos Estudos da Tradução e interpretação das línguas de sinais no Brasil a partir de artigos científicos. Orientadora Neiva de Aquino Albres. 2019. $69 \mathrm{f}$. Trabalho de conclusão de curso - TCC. (curso de Letras Libras - bacharelado em tradução/interpretação) Universidade Federal de Santa Catarina - UFSC, Florianópolis, 2019.

MOTTA-ROTH, D. (org.). Redação acadêmica: princípios básicos. 3. ed. Santa Maria: UFSM, Imprensa Universitária, 2003.

PAES, José Paulo. Tradução, a ponte necessária: aspectos e problemas da arte de traduzir. São Paulo: Editora Ática, 1990.

RODRIGUES, Carlo Henrique. Translation and Sign Language: High lighting the visual-gestural modality. Cadernos de Tradução. Florianópolis, v. 38, n. 2, p. 294319, Aug. 2018.2 Disponível em: http://www.scielo.br/scielo.php?script=sci_arttext\&pid=S2175-

79682018000200294\&Ing=en\&nrm=iso. Acesso em 30 Abr 2020.

ROSSI, Ana Helena. Traduzir: aspectos metodológicos e didáticos no ensino da tradução. In: FERREIRA, Alice M de A. GOROVITZ, Sabine (Org.). A Tradução na Sala de Aula: ensaios de teoria e prática de tradução. Brasília: Editora UnB, 2014. $219 \mathrm{p}$.

SALDANHA, Gabriela, O'BRIEN, Sharon. Research methodologies in translation studies. Book review. Journal of research design and statistics in linguistics and communication science. University of Birmingham. Routledge. New York, NY. $2014 . \quad 145-151 . \quad$ Disponível em: $<$ https://journals.equinoxpub.com/index.php/JRDS/article/view/30024>. Acesso em: 15 Jan 2018.

SANTOS, Saionara Figueiredo. Tradução comentada do poema "Debussy", de Manuel Bandeira, para a Língua Brasileira de Sinais, Belas Infiéis, v. 5, n. 1, p. 93116, $2016 . \quad$ Disponível em: $<$ http://periodicos.unb.br/index.php/belasinfieis/article/view/11371 >. Acesso em: 21 jul 2019.

SANTOS, Silvana. A. Tradução/Interpretação de Língua de Sinais no Brasil: uma análise das teses e dissertações de 1990 a 2010. Orientadora: Ronice Muller de Quadros. 2013. 313 f. Tese (Doutorado em Estudos da Tradução) Universidade Federal de Santa Catarina - UFSC, Florianópolis, 2013. Disponível em: <https://repositorio.ufsc.br/bitstream/handle/123456789/122677/325007.pdf?sequ ence $=1$ \&isAllowed $=\mathrm{y}>$. Acesso em: 15 Jan 2018.

SOBRAL, A. Elementos para uma definição do estético segundo o Círculo de Bakhtin. In: As letras e o seu ensino - Anais da IX Semana de Letras da UFOP. Ouro Preto: Editora Aldrava Letras e Artes, 2006, p.11-21.

TORRES, Marie-Hélène Catherine. Por que e como pesquisar a tradução 
comentada? In: FREITAS, Luana Ferreira de; TORRES, Marie Hélène Catherine; COSTA, Walter Carlos (orgs). Literatura traduzida: tradução comentada e comentários da tradução. Fortaleza: Substânsia, 2017. pp15-35. (TransLetras; v. 2) Disponível em: <https://repositorio.ufsc.br/bitstream/handle/123456789/181534/Literatura\%20trad uzida.pdf? sequence=1\&isAllowed=y $>$. Acesso em: 21 jul 2019.

WILLIANS, Jenny; CHESTERMAN, Andrew. The Map: a beginner's guide to doing research in Translation Studies. Manchester: St. Jerome Publishing, 2002.

VASCONCELLOS, Maria Lúcia. Tradução e Interpretação de Língua de Sinais (TILS) na Pós-Graduação: a afiliação ao campo disciplinar "Estudos da Tradução". Cadernos de Tradução, Florianópolis, v. 2, n. 26, p. 119-143, out. 2010. Disponível em: $\quad<$ https://periodicos.ufsc.br/index.php/traducao/article/view/21757968.2010v2n26p119/14226>. Acesso em: 15 jan. 2020.

ZAVAGLIA, Adriana; RENARD, Carla M. C.; JANCZUR, Christine. A tradução comentada em contexto acadêmico: reflexões iniciais e exemplos de um gênero textual em construção. Aletria: Revista de Estudos de Literatura, [S.I.], v. 25, n. 2, p. 331-352, dez. 2015.2 Disponível em: <http://www.periodicos.letras.ufmg.br/index.php/aletria/article/view/8755>. Acesso em: 07 set. 2019.

WEININGER, Markus J.; et al. Quando múltiplos olhares geram diferentes experiências de tradução ao português de um poema em libras: o caso de "Homenagem Santa Maria" de Godinho (2013). Anais do IV Congresso Nacional de Pesquisas em Tradução e Interpretação de Libras e Língua Portuguesa, UFSC, Florianópolis-SC.2014. Disponível em:<http://www.congressotils.com.br/anais/2014/2949.pdf>. Acesso em: 14 jan. 2019.

Recebido em 07 de março de 2020. Aprovado em 04 de maio de 2020. 